Electrodeposition of highly ordered macroporous iridium oxide through selfassembled colloidal templates

Jin $\mathrm{Hu},{ }^{a}$ Mamdouh Abdelsalam, ${ }^{a}$ Philip Bartlett, ${ }^{a}$ Robin Cole, ${ }^{b}$ Yoshihiro Sugawara, ${ }^{b}$ Jeremy Baumberg, ${ }^{b}$ Sumeet Mahajan ${ }^{a, b}$ and Guy Denuault ${ }^{a}$

${ }^{a}$ School of Chemistry, University of Southampton, Southampton UK SO17 1BJ. Email: gd@soton.ac.uk

${ }^{b}$ NanoPhotonics Centre, Department of Physics, University of Cambridge, Cambridge $\mathrm{CB} 3 \mathrm{OHE}$

Please cite this paper as:

Journal of Materials Chemistry, 2009, 19, 3855-3858

The publisher's version of this paper is available here:

http://dx.doi.org/10.1039/B900279K

Related articles by Dr Guy Denuault can be found below:

S.A.G. Evans, J.M. Elliott, L.M. Andrews, P.N. Bartlett, P.J. Doyle, G.

Denuault, Detection of hydrogen peroxide at mesoporous platinum

microelectrodes, Anal. Chem., 74 (2002) 1322-1326. (doi:

10.1021/ac011052p)

T. Imokawa, K.-J. Williams, G. Denuault, Fabrication and Characterization of Nanostructured Pd Hydride pH Microelectrodes, Anal. Chem., 78 (2006) 265-271. (doi: 10.1021/ac051328j) 


\title{
Electrodeposition of highly ordered macroporous iridium oxide through self-assembled colloidal templates
}

\author{
Jin Hu, ${ }^{a}$ Mamdouh Abdelsalam, ${ }^{a}$ Philip Bartlett, ${ }^{a}$ Robin Cole, ${ }^{b}$ Yoshihiro Sugawara, ${ }^{b}$ Jeremy Baumberg, \\ Sumeet Mahajan ${ }^{b}$ and Guy Denuault $*^{a}$
}

\author{
${ }_{5}$ Received (in $\left.X X X, X X X\right)$ Xth $X X X X X X X X X 200 X$, Accepted Xth XXXXXXXXX $200 X$ \\ First published on the web Xth $X X X X X X X X X 200 X$ \\ DOI: $10.1039 / b 000000 x$
}

Iridium oxide electrodeposited through a self-assembled colloidal template has an inverse opal structure. Monolayers present long range hexagonal arrangements of hemispherical nanocavities

10 while multilayers present 3D honeycomb structures with spherical voids. The films are amorphous, have several electroactive redox states and are electrochromic. The nanostructure modifies their reflectivity thus indicating these films could be used as tunable photonic devices.

\section{Introduction}

Iridium oxide (IrOx) films are well known for their 15 applications in electrochromism, ${ }^{1,2}$ physiology ${ }^{3,4}$ and $\mathrm{pH}$ sensing. ${ }^{5-7}$ However, the preparation of plain IrOx films is not trivial and that of nanostructured IrOx films even more challenging. Many articles describe the preparation of IrOx nanoparticles, ${ }^{8}$ nanowires, ${ }^{9,} 10$ and nanocrystals ${ }^{11,12}$ but very 20 few report the preparation of nanostructured IrOx films. ${ }^{13,} 14$ Here we describe, for the first time, the fabrication of highly ordered micrometre thick macroporous films of iridium oxide using electrodeposition through a self-assembled colloidal template. The films are grown by potentiostatic cycling in an 25 iridium complex solution. A few cycles produce highly ordered arrays of hemispherical cups with long range hexagonal symmetry. Growth can be finely controlled via the cycle number and structures ranging from fully open to partially closed cups can be prepared. Further cycling yields 30 porous films up to 3 template layers thick with a 3D honeycomb internal structure. Upon characterisation with XRay diffraction, Raman spectroscopy, SEM, voltammetry, and reflectivity measurements, the films are found to be amorphous, to have structural dimensions faithful to that of 35 the template, several electroactive redox states and reflectivity spectra significantly different from that of non-structured films. Such films should find applications in biology (IrOx is conducting, non reactive and biocompatible) but particularly optics because their optical density can be electrochemically 40 controlled and the cavity diameters correspond to UV-visible wavelengths.

\section{Experimental}

Gold electrodes and colloidal templates were prepared and characterised as described previously ${ }^{15}$. The $\mathrm{IrOx}$ deposition ${ }_{45}$ solution $^{16}$ was prepared as follows: Anhydrous $\mathrm{IrCl}_{4}(0.07 \mathrm{~g}$, Alfa-Aesar) was dissolved in $50 \mathrm{ml}$ of water then stirred for $30 \mathrm{~min}$. Aqueous $\mathrm{H}_{2} \mathrm{O}_{2}(0.5 \mathrm{ml}, 30 \%$, Aldrich) was added and the resulting solution was stirred for $10 \mathrm{~min}$. Oxalic acid dehydrate ( $\sim 250 \mathrm{mg}$, Aldrich) was added and the solution was 50 stirred for another $10 \mathrm{~min}$. The $\mathrm{pH}$ was slowly adjusted to
10.5 by addition of potassium carbonate (Aldrich). The resulting yellowish brown solution was covered and left at room temperature for $3-4$ days to stabilise after which it appeared deep purple. The deposition of IrOx was carried out 55 by cyclic voltammetry between -0.8 and $+0.7 \mathrm{~V}$ vs. SCE at $100 \mathrm{mV} \mathrm{s}^{-1}$ with a PGSTAT30 (Autolab, Eco Chemie) with the cell inside a grounded Faraday cage. The template was dissolved with dimethylformamide under sonication and the films were washed in pure water. Scanning electron images 60 were acquired with an XL30 ESEM (Philips) and a JSM 6500F (Jeol). Raman spectra were recorded on a Renishaw Raman 2000 microscope with a $633 \mathrm{~nm}$ HeNe laser and a 1 $\mu \mathrm{m}$ diameter spot size. Reflectivity spectra were carried out with a coherent white-light source with the sample mounted 65 on a goniometric stage ${ }^{17}$.

\section{Results and discussion}

IrOx films are produced by electrochemical oxidation of iridium electrodes, ${ }^{18,}{ }^{19}$ thermal decomposition of iridium salts, ${ }^{20}$ reactive sputtering, ${ }^{21}$ chemical vapour deposition, ${ }^{14}$ 70 mixing solid $\mathrm{IrO}_{2}$ with a matrix ${ }^{22}$ or by electrodeposition from a soluble precursor. ${ }^{16,23}$ The latter was chosen because of our experience in the templated electrodeposition of nanostructured materials. ${ }^{24-28}$ Templated electrodeposition has proved to be an excellent means to tune the properties of 75 materials by modifying their structure rather than their elemental composition. Using this method, nanostructured gold films are prepared to control surface plasmons and produce tuneable photonic surfaces ${ }^{15,29-33}$ and to amplify Surface Enhanced Raman signals ${ }^{34,} 35$ or control wetting and 80 design hydrophobic surfaces. ${ }^{36}$ Similarly nanostructured templated $\mathrm{Ni}_{80} \mathrm{Fe}_{20}$ films are prepared with different coercitivities by selecting templates with different dimensions. $^{37,} 38$ In all cases, the internal geometry and the dimensions of the cavities determine the properties of the 85 material.

The template is prepared by placing a drop of colloidal suspension of monodisperse spheres onto a gold coated glass slide and controlling solvent evaporation to produce a deposit of spheres. Driven by capillary forces the spheres assemble 


\section{Insert Figure 1A here}

Insert Figure 1B here

Fig. 1 Voltammograms for the growth of IrOx films on gold electrodes 5 recorded in the deposition solution at $100 \mathrm{mV} \mathrm{s}^{-1}$. A) no template, B) with a $600 \mathrm{~nm}$ diameter polystyrene template. Voltammetric cycle numbers are indicated against corresponding line styles. The current density was calculated using the geometric electrode area.

into long range, hexagonal close packed arrays ${ }^{39}$ which form 10 the mould for the electrodeposition. Adsorbing a cysteamine monolayer onto the gold substrate improves its wettability and controls its surface charge to help anchor the first layer of spheres. ${ }^{40}$ To produce a film the substrate and its template are immersed in an electrolyte containing a precursor (a salt or a 15 complex) and the substrate is connected to a potentiostat which drives the deposition. Growth occurs within the voids between the spheres. The spheres are removed by dissolution and the film obtained is the cast of the template. Thicknesses ranging from fractions of a template layer to several template 20 layers can be obtained by adjusting the deposition time. Up to $1 / 2 d$ where $d$ is the sphere diameter, the film consists of a hexagonal arrangement of sphere segment cups. Beyond $1 / 2 d$, the film turns into a network of interconnecting sphere and sphere segment cavities akin to a reticulated three dimensional 25 honeycomb construction. The film structure is tailored by selecting the diameters of the spheres (typically between 100 $\mathrm{nm}$ and $2 \mu \mathrm{m}$ ) and the deposition time. The procedure has been used to prepare metals and alloys, $25,38,41,42$ semiconductors, ${ }^{43}$ conducting polymers ${ }^{26,44}$ and oxides. ${ }^{45-47}$

30

Insert Figure 2 here

Fig. 2 Anodic $(\boldsymbol{\Lambda}, \bullet)$ and cathodic $(\Delta, \circ)$ charge densities recorded during film growth for a structured film (triangles) and a flat film (circles) against the number of voltammetric cycles. Conditions similar to Fig. 1.

35 The preparation of IrOx films followed the recipe reported by Yamanaka. ${ }^{16}$ Fig. 1 shows a typical set of voltammograms recorded during deposition. In absence of template, Fig. 1A, the voltammograms are similar to those produced by potential cycling of an iridium wire in acid. ${ }^{1,} 41$ The larger current 40 density observed when depositing with the template, Fig. 1B, suggests a greater efficiency, possibly because the homogeneous reaction ${ }^{16}$ which leads to the oxide deposition is confined within the voids of the template. The voltammograms are much less slanted, thus suggesting a better conductivity in 45 the structured film. The anodic and cathodic peaks have been reported to correspond to the transitions between three different oxidation states, namely $\operatorname{Ir}(\mathrm{III})$ for $E<\mathrm{C} 1$, $\operatorname{Ir}(\mathrm{IV})$ for A1 $<E<\mathrm{C} 2$ and $\operatorname{Ir}(\mathrm{V})$ for $E>\mathrm{A} 2 .^{23}$ During the growth of templated films, the charge passed depends almost linearly on 50 the number of voltammetric cycles, Fig. 2, and the anodic to cathodic charge ratio is equal to one at all cycle numbers. This suggests that the whole of the film is reversibly oxidised and reduced during cycling and demonstrates that cyclic voltammetry provides a fine degree of control over the 55 amount of oxide deposited. Results are markedly different with flat films. Further voltammetric characterisation of the films in basic conditions (0.1 $\left.\mathrm{M} \mathrm{Na}_{2} \mathrm{CO}_{3}, \mathrm{pH} 10.9\right)$ (in acid the templated films have broad voltammetric peaks harder to analyse) produced a linear relationship between the peak 60 currents and the scan rate therefore indicating the absence of kinetic effects over the $20-200 \mathrm{mV} \mathrm{s}^{-1}$ range studied. Both flat and structured films were seen to change colour during potential cycling (from transparent for $E<0.3 \mathrm{~V}$ vs. SCE to dark blue for $E>0.5 \mathrm{~V}$ vs. SCE) thus indicating that the 65 electrochromism of the IrOx films did not disappear with the templated structure.

Insert Figure 3 here

Fig. 3 Micrographs of IrOx films produced by cyclic voltammetry (same 70 conditions as in Fig. 1) with a $600 \mathrm{~nm}$ diameter polystyrene template. A) $\sim 20$ cycles, B) $\sim 40$ cycles, $h \sim 1 / 4 d$, C) $\sim 60$ cycles, $h \sim 1 / 2 d$, D) $\sim 80$ cycles, E) $\sim 100$ cycles, $h \sim d$, F) $\sim 200$ cycles, $h>d$

In Fig. 3, SEM micrographs taken at different stages of deposition show the remarkable structure of the film left after 75 removal of the template. Initially, Fig. 3A, the presence of the deposit is only confirmed by the difference in contrast between the gold substrate and IrOx but the hexagonal symmetry is already obvious. After fewer than ten cycles the shape of the deposit appears, Fig. 3B, but the underlying 80 granular structure of the substrate is still clearly visible. When the film thickness, $h$, reaches a height of $\sim 1 / 2 d$, Fig. 3C, the smooth wall of the IrOx cups can be seen. The cup diameters follow closely that of the polystyrene spheres of the template. Except for the cup rims which show variations in texture, Fig. $853 \mathrm{D}$, the film is uniform and free from defects over a very long range. Beyond $1 / 2 d$, the cups gradually close, Fig. $3 \mathrm{E}$ but again the films are virtually free of defects. Fig. 3F shows a typical film grown through several template layers; the 3D honeycomb internal structure characteristic of inverted opals 90 is clearly visible. Up to one template layer, the film thickness measured by SEM is found to be linearly related to the number of voltammetric cycles (similar results are found with films deposited without template). Beyond $1 d$, it has not been possible to establish the relationship between cycle number 95 and film thickness as the later becomes difficult to measure. Furthermore an evaluation of the thickness deposited from the charge passed and account of the interstitial volume within the template necessitates measuring the density of the deposit as the porosity of the material is reported to produce significant 100 differences between the density of bulk IrOx, circa $11 \mathrm{~g} \mathrm{~cm}^{-3}$, and that of electrodeposited films circa $2 \mathrm{~g} \mathrm{~cm}^{-3} .^{23}$ Characterisation with X-Ray diffraction only produced a spectrum for the underlying gold substrate. However Raman microscopy clearly showed that the material was amorphous 105 as deposited but became crystalline after annealing at $460^{\circ} \mathrm{C}$.

Insert Figure 4A here

Insert Figure 4B here

Fig. 4 Normalised reflectivity spectra recorded on A) a non-structured 110 film and B) a structured film supporting plasmon, $\sim 1 / 2 d$, in air but with the films taken out of the solution in the bleached state. 
Angle resolved reflectivity spectra of structured and nonstructured IrOx films ( $1 / 2 d$ thick), Fig. 4, clearly demonstrate that, as with gold films, ${ }^{33}$ the presence of the nanostructure imparts new optical properties to the material. In the case of 5 the flat film, Fig. 4A, the reflectivity spectrum (normalized to the reflectivity from an aluminum mirror) changes in intensity with angle of incidence but does not change in wavelength or shape. For the structured film, Fig. 4B, in contrast there is a clear change in the position of minimum reflectivity with 10 angle. Two plasmon bands are observed in the data, Bragg diffracted by the periodicity of the dishes into the plane of the surface. The dispersion of these modes is governed by the high refractive index IrOx layer and the size of the dishes $d$. Initially coupled at $0^{\circ}$ incidence, these modes tune to shorter 15 wavelength with increasing incident angle, indicative of delocalized behavior. Electrochromism was also observed when reflectivity spectra were recorded under potentiostatic control. For example, the intensity reflected at $770 \mathrm{~nm}$ varried from $100 \%$ at $-0.3 \mathrm{~V}$ (the bleached state) to $67 \%$ at $0 \mathrm{~V}, 34 \%$ 20 at $+0.1 \mathrm{~V}, 21 \%$ at $+0.2 \mathrm{~V}$ and $16 \%$ at $+0.7 \mathrm{~V}$ (the dark state). Detailed results recorded under potentiostatic control for different thicknesses will be reported subsequently.

\section{Conclusions}

This article reports the first successful preparation of highly 25 ordered iridium oxide films via electrodeposition through a self-assembled colloidal template of polystyrene spheres. The films are true casts of the template; monolayer films present a long range hexagonal arrangement of hemispherical cavities while multilayer films present a 3D honeycomb structure with 30 spherical voids characteristic of inverse opal structures. This approach avoids the shrinkage normally observed with chemical and thermal transformations. The films are found to be amorphous, to have several electroactive redox states and to be electrochromic. Compared to flat films the reflectivity of 35 structured films is found to depend on the angle of incidence and wavelength of the incident light. These preliminary optical results suggest that nanostructured IrOx films could be used as electrochemically or chemically ( $\mathrm{IrOx}$ is $\mathrm{pH}$ sensitive) tunable photonic devices.

\section{${ }_{40}$ Acknowledgements}

The financial supports of the EPSRC (EP/C511786/1) and of the Dorothy Hodgkin Foundation are gratefully acknowledged.

\section{Notes and references}

${ }_{45}{ }^{a}$ School of Chemistry, University of Southampton, Highfield, Southampton, SO17 1BJ, UK, E-mail: gd@soton.ac.uk Fax: +44 (0)23 80593781; Tel: +44 (0)23 80592154;

${ }^{b}$ NanoPhotonics Centre, Department of Physics, University of Cambridge, JJ Thomson Ave, Cambridge, CB3 OHE,UK, E-mail:

50 j.j.baumberg@phy.cam.ac.uk. Fax: +44 (0)1223 764515; Tel: +44 (0)1223 337313;

\section{References}

1. G. Beni, J. L. Shay, S. Gottesfeld and D. E. McIntyre, Appl. Phys. Lett., 1978, 33, 208-210.

55 2. J. D. E. McIntyre, W. F. Peck and S. Nakahara, J Electrochem Soc, 1980, 127, 1264-1268.

3. R. D. Meyer, S. F. Cogan, T. H. Nguyen and R. D. Rauh, Ieee Transactions on Rehabilitation Engineering, 2001, 9, 2-11.

4. S. C. Mailley, M. Hyland, P. Mailley, J. M. McLaughlin and E. T.

$60 \quad$ McAdams, Materials Science \& Engineering C-Biomimetic and Supramolecular Systems, 2002, 21, 167-175.

5. D. O. Wipf, F. Y. Ge, T. W. Spaine and J. E. Bauer, Anal Chem, 2000, 72, 4921-4927.

6. K. G. Kreider, M. J. Tarlov and J. P. Cline, Sensors and Actuators, B: 65 Chemical, 1995, B28, 167-172.

7. I. A. Ges, B. L. Ivanov, D. K. Schaffer, E. A. Lima, A. A. Werdich and F. J. Baudenbacher, Biosens Bioelectron, 2005, 21, 248256

8. T. Pauporte, F. Andolfatto and R. Durand, Electrochim Acta, 1999, 70 45, 431-439.

9. R. S. Chen, Y. S. Huang, Y. M. Liang, D. S. Tsai and K. K. Tiong, Journal of Alloys and Compounds, 2004, 383, 273-276.

10. F. Y. Zhang, R. Barrowcliff, G. Stecker, W. Pan, D. L. Wang and S. T. Hsu, Jpn. J. Appl. Phys. Part 2 - Lett. Express Lett., 2005, 75 44, L398-L401.

11. R. S. Chen, A. Korotcov, Y. S. Huang and D. S. Tsai, Nanotechnology, 2006, 17, R67-R87.

12. A. Korotcov, Y. S. Huang, D. S. Tsai and K. K. Tiong, Journal of Physics-Condensed Matter, 2006, 18, 1121-1136.

80 13. A. M. Serventi, M. A. El Khakani, R. G. Saint-Jacques and D. G. Rickerby, Journal of Materials Research, 2001, 16, 23362342.

14. Y. L. Chen, C. C. Hsu, Y. H. Song, Y. Chi, A. J. Carty, S. M. Peng and G. H. Lee, Chemical Vapor Deposition, 2006, 12, 442 85447

15. P. N. Bartlett, J. J. Baumberg, S. Coyle and M. E. Abdelsalam, Faraday Discuss., 2004, 125, 117-132.

16. K. Yamanaka, Japanese Journal of Applied Physics Part 1-Regular Papers Short Notes \& Review Papers, 1989, 28, 632-637.

90 17. M. C. Netti, M. D. B. Charlton, G. J. Parker and J. J. Baumberg, Appl. Phys. Lett., 2000, 76, 991-993.

18. M. Huppauff and B. Lengeler, J Electrochem Soc, 1993, 140, 598602.

19. M. Wang, S. Yao and M. Madou, Sens. Actuator B-Chem., 2002, 81, 95 313-315.

20. C. Mousty, G. Foti, C. Comninellis and V. Reid, Electrochim Acta, 1999, 45, 451-456.

21. L. M. Schiavone, W. C. Dautremontsmith, G. Beni and J. L. Shay, Appl. Phys. Lett., 1979, 35, 823-825.

100 22. J. Yano, K. Noguchi, S. Yamasaki and S. Yamazaki, Electrochem Commun, 2004, 6, 110-114.

23. M. A. Petit and V. Plichon, Journal of Electroanalytical Chemistry, 1998, 444, 247-252.

24. G. S. Attard, P. N. Bartlett, N. R. B. Coleman, J. M. Elliott, J. R. $105 \quad$ Owen and J. H. Wang, Science, 1997, 278, 838-840.

25. P. N. Bartlett, P. R. Birkin and M. A. Ghanem, Chem Commun, 2000, 1671-1672. 
26. P. N. Bartlett, P. R. Birkin, M. A. Ghanem and C. S. Toh, J Mater Chem, 2001, 11, 849-853.

27. S. A. G. Evans, J. M. Elliott, L. M. Andrews, P. N. Bartlett, P. J. Doyle and G. Denuault, Anal Chem, 2002, 74, 1322-1326.

5 28. T. Imokawa, K.-J. Williams and G. Denuault, Anal Chem, 2006, 78, 265-271.

29. T. A. Kelf, Y. Sugawara, J. J. Baumberg, M. Abdelsalam and P. N. Bartlett, Physical Review Letters, 2005, 95.

30. G. V. Prakash, L. Besombes, T. Kelf, J. J. Baumberg, P. N. Bartlett

10 and M. E. Abdelsalam, Opt Lett, 2004, 29, 1500-1502.

31. S. Coyle, G. V. Prakash, J. J. Baumberg, M. Abdelsalem and P. N. Bartlett, Appl. Phys. Lett., 2003, 83, 767-769.

32. S. Coyle, M. C. Netti, J. J. Baumberg, M. A. Ghanem, P. R. Birkin, P. N. Bartlett and D. M. Whittaker, Physical Review Letters, 2001, 8717.

15

33. M. C. Netti, S. Coyle, J. J. Baumberg, M. A. Ghanem, P. R. Birkin, P. N. Bartlett and D. M. Whittaker, Adv Mater, 2001, 13, 1368-1370.

34. S. Cintra, M. E. Abdelsalam, P. N. Bartlett, J. J. Baumberg, T. A.

20 Kelf, Y. Sugawara and A. E. Russell, Faraday Discuss., 2006, 132, 191-199.

35. M. E. Abdelsalam, P. N. Bartlett, J. J. Baumberg, S. Cintra, T. A. Kelf and A. E. Russell, Electrochem Commun, 2005, 7, 740744.

25 36. M. E. Abdelsalam, P. N. Bartlett, T. Kelf and J. Baumberg, Langmuir, 2005, 21, 1753-1757.

37. A. A. Zhukov, M. A. Ghanem, A. Goncharov, P. A. J. de Groot, I. S. El-Hallag, P. N. Bartlett, R. Boardman and H. Fangohr, Journal of Magnetism and Magnetic Materials, 2004, 272-76,

30 1621-1622.

38. P. N. Bartlett, M. A. Ghanem, I. S. El Hallag, P. de Groot and A. Zhukov, J Mater Chem, 2003, 13, 2596-2602.

39. N. D. Denkov, O. D. Velev, P. A. Kralchevsky, I. B. Ivanov, H. Yoshimura and K. Nagayama, Langmuir, 1992, 8, 3183-3190.

35 40. M. Kawasaki, T. Sato and T. Yoshimoto, Langmuir, 2000, 16, 54095417.

41. L. D. Burke and R. A. Scannell, Platinum Metals Review, 1984, 28, $56-61$. 